\title{
Half-and-Half Palatoplasty
}

\author{
Hyun Ho Han, \\ In Sook Kang, \\ Jong Won Rhie \\ Department of Plastic and Reconstructive \\ Surgery, Seoul St. Mary's Hospital, College of \\ Medicine, The Catholic University of Korea, \\ Seoul, Korea
}

No potential conflict of interest relevant to this article was reported.

\begin{abstract}
A 14-month-old child was diagnosed with a Veau Class II cleft palate. Von Langenbeck palatoplasty was performed for the right palate, and $\mathrm{V}-\mathrm{Y}$ pushback palatoplasty was performed for the left palate. The child did not have a special problem during the surgery, and the authors were able to elongate the cleft by $10 \mathrm{~mm}$. Contrary to preoperative concerns regarding the hybrid use of palatoplasties, the uvula and midline incisions remained balanced in the middle. The authors named this combination method "halfand-half palatoplasty" and plan to conduct a long-term follow up study as a potential solution that minimizes the complications of palatoplasty.
\end{abstract}

Keywords: Cleft palate / Congenital abnormalities / Craniofacial abnormalities / Surgery

\section{INTRODUCTION}

Cleft palate can cause problems such as speaking disability, eating difficulty, accumulation of fluid in the middle ear and malocclusion. Palatoplasty, by filling up the cleft in the palate, ultimately extends the length of the palate, enables normal pronunciation by re-establishing the levator sling, and minimizes the growth restriction of the maxillary bone. A number of surgical methods have been developed to achieve these goals. Common surgical methods include von Langenbeck palatoplasty, V-Y pushback palatoplasty, two-flap palatoplasty and double-opposing palatoplasty. Various surgical methods are used according to surgeon preference and relevant patient factors, and have individual advantages and disadvantages.

Von Langenbeck and V-Y pushback palatoplasty were introduced at the earliest stage and are still widely used. Von Langenbeck procedure is performed by elevation and approximation of

Correspondence: Jong Won Rhie

Department of Plastic and Reconstructive Surgery, Seoul St. Mary's Hospital, College of Medicine, The Catholic University of Korea, 222 Banpo-daero, Seocho-gu, Seoul 137-701, Korea

E-mail: rhie@catholic.ac.kr

Received June 23, 2014 / Revised July 16, 2014 / Accepted August 1, 2014 bipedicled flaps along the midline to repair the cleft palate. Its disadvantage is dissatisfactory speech due to the difficulty in cleft elongation and limitations in soft-palate movement. Its advantage is relatively little effect on the maxillary growth due to the small surface area of secondary healing over the denuded hard palate [1]. Although V-Y pushback palatoplasty enables palate length extension and levator veli palatini attachment within the same direction, it may impair the maxillary growth due to contracture from the larger defect [2]. Reported herein is a novel method, "half-andhalf palatoplasty", which addresses disadvantages of both von Langenbeck and pushback palatoplasty .

\section{CASE REPORT}

A 13-month-old female child diagnosed with cleft palate Veau Class II underwent a corrective operation. She was found to have a relatively large cleft in the hard palate posterior to the incisive foramen and through the middle of the soft palate (Fig. 1).

Preoperatively, the authors had to account for palatal speech capabilities and maxillary growth of the child in the future. At first, double opposing palatoplasty was considered but not chosen due to the large cleft. Intraoperatively, von Langenbeck palato- 
plasty was performed on the right palate, and V-Y pushback palatoplasty was performed on the left side (Fig. 2). On the right side, a medial incision was made along the cleft edge, and a lateral relaxation incision was performed from the maxillary tuberosity to the posterior portion of the alveolar ridge. Then, the bipedicled mucoperiosteal palatal flap was elevated. The same method was used on the left side, and then an oblique incision that joined the medial incision and the lateral relaxation incision was designed. Both flaps, on the oral side and on the nasal side, were elevated. The flaps were made more mobile via skeletalization around the neurovascular pedicle arising from the greater palatine foramen. The palate was closed sequentially, beginning with the nasal side, using 4-0 Vicryl suture. A both side based vomer flap was used in the anterior part of the nasal side to loosen the tension due to the wide cleft interval, and intravelar veloplasty was performed simultaneously to relocate the levator sling to its original position. The left flap of the oral side was backed astern. Then the closure was performed without tension, by approximating the midline, using 4-0 Vicryl suture. The surgery was completed after maximum approximation suture was performed to decrease the surface of the denuded bone at the lateral relaxation incision site on both sides.

The novel method, named "half-and-half palatoplasty," was performed by combining von Langenbeck palatoplasty on the right side and V-Y pushback palatoplasty on the left side (Fig. 3). Contrary to concerns regarding the combination of operations, the uvula and midline incision remained balanced in the middle. The result of veloplasty was stable, and the palate lengthened by 10 $\mathrm{mm}$ along the midline. The patient was discharged home with her
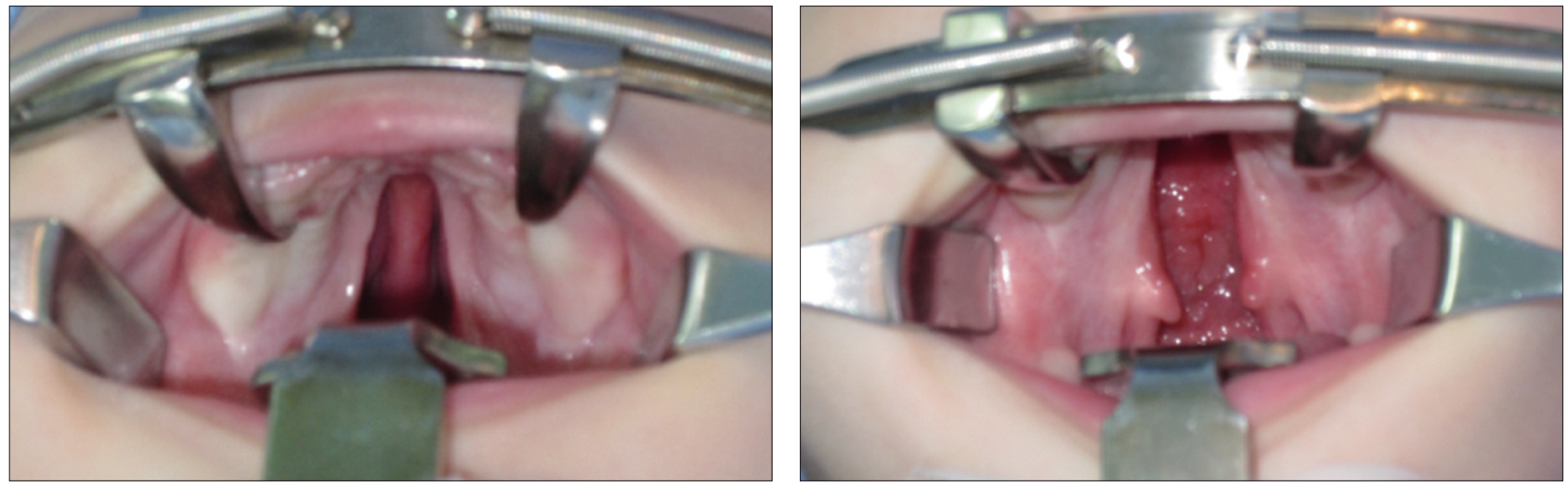

Fig. 1. Preoperative views (Veau Class II cleft palate). The cleft was $15 \mathrm{~mm}$ in terms of maximal width in the intertuberosity region.
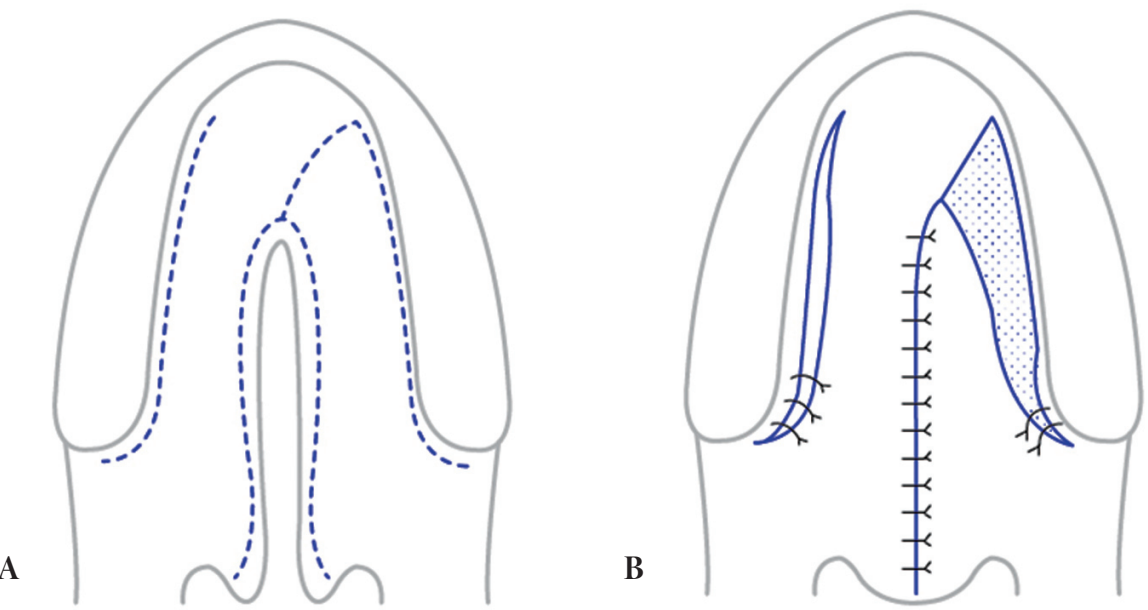

Fig. 2. Diagram of half-and-half palatoplasty. (A) Incision line. (B) Postoperative result. 
parents on day 5 postsurgery. There were no complications such as fistula formation or wound disruption at outpatient clinic visits (Fig. 4). At 15 months after surgery, we did not observe abnormality of maxillary growth in this patient. The child is expected to undergo speech assessment soon.

\section{DISCUSSION}

There have been many advances in palatoplasty after von Langenbeck introduced his solution to cleft palates in the 1800s [3]. Despite this long history, there are no established theories on the timing and method of repair, and the decision depends largely on the surgeon. The important thing is that the common purpose of these surgical methods is not limited to filling the cleft in the palate. Enabling a child to speak with normal pronunciation and minimizing the retardation of maxillary growth have also become important factors. In this context, the authors have devised a novel method, "half-and-half palatoplasty," which combines von Langenbeck palatoplasty and V-Y pushback palatoplasty.

Technically, the V-Y pushback palatoplasty is a modification of von Langenbeck palatoplasty. Since it is difficult to elongate the palate in von Langenbeck palatoplasty, the authors were searching for a way to lengthen the palate. To achieve this, the mucoperiosteal flap was divided at the anterior portion with the circulation provided solely by the greater palatine vessel (the posterior pedicle), and backed astern to the anteroposterior vector. In a

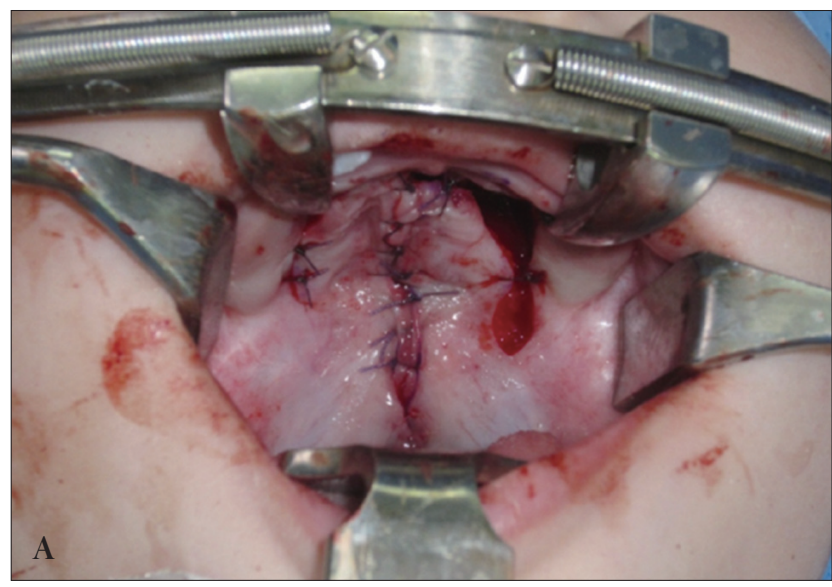

Fig. 3. Immediate postoperative views. (A) von Langenbeck palatoplasty. (B) Pushback palatoplasty.

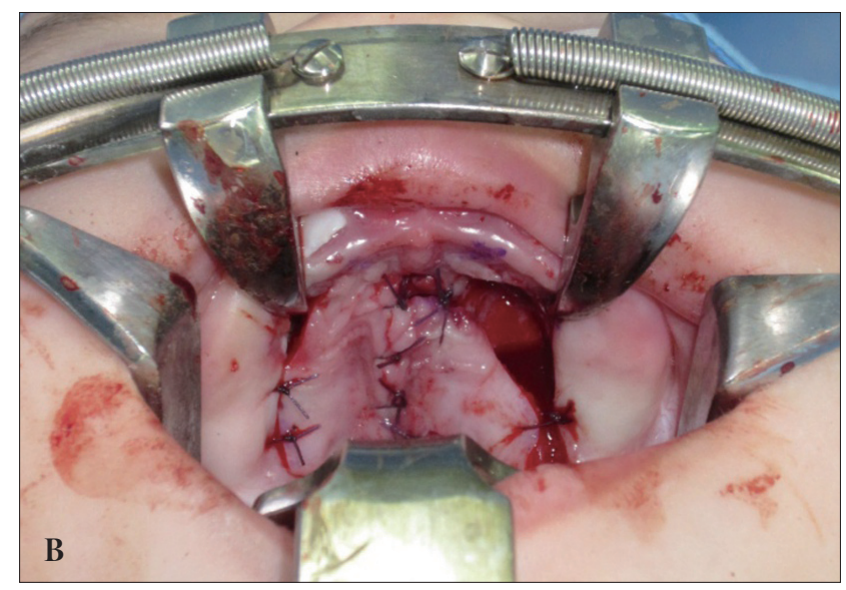

long-term follow-up, the V-Y pushback technique was found to elongate the palate by $15-20 \mathrm{~mm}$ [2], which had significantly improved the pronunciation [4]. However, the denuded palate, which was produced by reversing the flap, had a negative impact on maxillary growth [5,6], and the fistula rate was increased [7].

Parwaz et al. [8] reported an increased rate of fistula for those who had cleft widths greater than $15 \mathrm{~mm}$ and received Furlow's double opposing Z-plasty. Thus, half-and-half palatoplasty could be an alternative for cleft palates with width greater than $15 \mathrm{~mm}$.

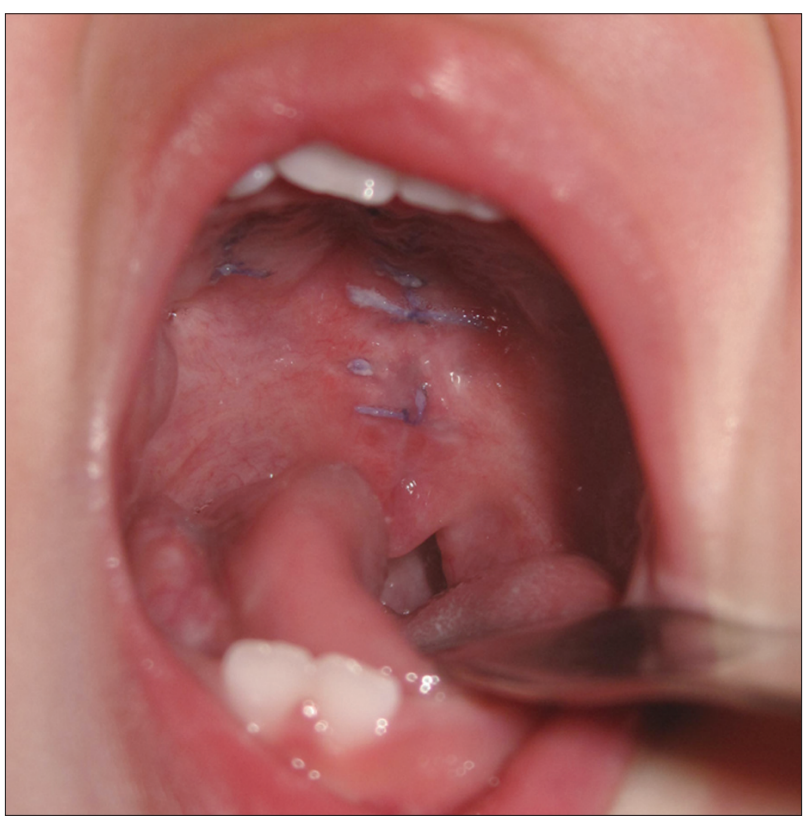

Fig. 4. One-month postoperative view. 
Although the palatal lengthening in half-and-half palatoplasty (by about $10 \mathrm{~mm}$ ) is less than that in V-Y pushback palatoplasty (about 15-20 mm), the rate of the bone denudation decreased more significantly in half-and-half palatoplasty. Since different surgical methods were used on between the sides, the authors expected the midline to shift toward the relatively less mobile flapthe side in which von Langenbeck technique was performed. Despite these concerns, the incision remained in the middle, and did not lean toward either side. The symmetry of levator sling was yet another concern. Yet, the functional importance of symmetrically locating the flap in the middle is still unknown in cleft palate repair. Although a symmetrical flap might have an aesthetic importance, the authors did not consider a symmetrical flap to be as important as the functional problems such a flap would cause after a long-term follow-up. In conclusion, to compare the preceding matters that were discussed, a long-term (more than 10 years) follow-up of patients who had undergone half-and-half palatoplasty is considered meaningful. The pronunciation, velopharyngeal competence, difference between each side of velopharyngeal gap, and maxillary growth of the child who underwent half-and-half palatoplasty should be objectively evaluated after several other patients have undergone the procedure.

\section{REFERENCES}

1. Blocksma R, Leuz CA, Beernink JH. A study of deformity following cleft palate repair in patients with normal lip and alveolus. Cleft Palate J 1975;12:390-9.

2. Krause CJ, Tharp RF, Morris HL. A comparative study of results of the von Langenbeck and the V-Y pushback palatoplasties. Cleft Palate J 1976;13:11-9.

3. Goldwyn RM. Bernhard Von Langenbeck. His life and legacy. Plast Reconstr Surg 1969;44:248-54.

4. Van Lierde KM, Monstrey S, Bonte K, Van Cauwenberge P, Vinck B. The long-term speech outcome in Flemish young adults after two different types of palatoplasty. Int J Pediatr Otorhinolaryngol 2004;68: 865-75.

5. LaRossa D. The state of the art in cleft palate surgery. Cleft Palate Craniofac J 2000;37:225-8.

6. Pigott RW, Albery EH, Hathorn IS, Atack NE, Williams A, Harland K, Orlando A, Falder S, Coghlan B. A comparison of three methods of repairing the hard palate. Cleft Palate Craniofac J 2002;39:383-91.

7. Cohen SR, Kalinowski J, LaRossa D, Randall P. Cleft palate fistulas: a multivariate statistical analysis of prevalence, etiology, and surgical management. Plast Reconstr Surg 1991;87:1041-7.

8. Parwaz MA, Sharma RK, Parashar A, Nanda V, Biswas G, Makkar S. Width of cleft palate and postoperative palatal fistula--do they correlate? J Plast Reconstr Aesthet Surg 2009;62:1559-63. 